\title{
Influences of environmental and chemical parameters on the spatial growth patterns of four riverine cyprinid fishes
}

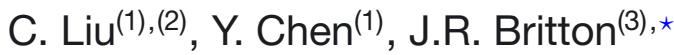 \\ Received March 23, 2015 \\ Revised April 14, 2015 \\ Accepted April 16, 2015
}

\section{ABSTRACT}

Key-words: $\quad$ Understanding intraspecific variability in fish somatic growth rates is imroach, chub, portant as growth is a key life history trait that plays a fundamental role in many biological and ecological processes. Here, the influence of envidisturbance, somatic growth, environmental ronmental and chemical parameters was tested on intraspecific variability in growth rates of the cyprinid fishes roach Rutilus rutilus, chub Squalius cephalus and dace Leuciscus leuciscus across 13 rivers in England, change and also compared with those for barbel Barbus barbus from the same rivers. Outputs indicated that growth rate responses to the parameters were species-specific, with more significant effects generally detected on juvenile growth than lifetime growth. For $R$. rutilus and $S$. cephalus, latitude (as a surrogate of temperature) was the most significant predictor of their growth rates, with growth rates decreasing as latitude increased. Contrary to prediction, aspects of degraded water quality accelerated the growth rates of these fishes, except in $B$. barbus, although concentrations of nitrogenous compounds were below toxicity thresholds. This emphasizes the ability of populations of these cyprinid fishes to tolerate some environmental disturbances and, in entirety, suggests that the intraspecific variability in the growth rates of these fishes is significantly influenced by abiotic parameters and their association with levels of anthropogenic disturbance.

\section{RÉSUMÉ}

Influences de paramètres environnementaux et chimiques sur les modèles de croissance spatialisés de quatre cyprinidés fluviaux

Mots-clés : gardon, chevesne, perturbation,
Comprendre la variabilité intraspécifique des taux de croissance somatique de poissons est important car la croissance est un trait d'histoire de vie clé qui joue un rôle fondamental dans de nombreux processus biologiques et écologiques. Ici, l'influence des paramètres environnementaux et chimiques a été testée sur la variabilité intraspécifique des taux de croissance des cyprinidés, gardon Rutilus rutilus, chevesne Squalius cephalus et vandoise Leuciscus leuciscus de 13 rivières

(1) Laboratory of Biological Invasion and Adaptive Evolution, Institute of Hydrobiology, Chinese Academy of Sciences, Wuhan, P.R. China

(2) Graduate University of the Chinese Academy of Sciences, Beijing, P.R. China

(3) Department of Life and Environmental Sciences, Faculty of Science and Technology, Bournemouth University, Fern Barrow, Poole, Dorset, UK

* Corresponding author: rbritton@bournemouth.ac.uk 
croissance somatique, changements environnementaux en Angleterre, mais aussi sur ceux du barbeau Barbus barbus des mêmes rivières. Les résultats indiquent que les réponses des taux de croissance à ces paramètres sont spécifiques de l'espèce, avec des effets plus importants généralement détectés sur la croissance des juvéniles que ceux détectés sur la croissance sur toute la vie. Pour $R$. rutilus et $S$. cephalus, la latitude (comme substitut de la température) est le facteur prédictif le plus important de leur taux de croissance, avec des taux de croissance diminuant à mesure que la latitude augmente. Contrairement à la prédiction, l'aspect dégradé de la qualité de l'eau accélère les taux de croissance de ces poissons, sauf pour $B$. barbus, alors que les concentrations des composés azotés sont inférieures aux seuils de toxicité. Cela souligne la capacité des populations de ces cyprinidés à tolérer certaines perturbations de l'environnement et, en tout cas, suggère que la variabilité intraspécifique dans les taux de croissance de ces poissons est fortement influencée par des paramètres abiotiques et leur association avec le niveau de perturbation anthropique.

\section{INTRODUCTION}

Identifying the factors affecting fish growth rates is important ecologically due to the importance of growth as a key life history trait and its role in, for example, production and juvenile recruitment (Brandt et al., 1992; Berkeley et al., 2004). In the freshwater phase of stream-dwelling salmonid fishes, biotic factors are important determinants of individual growth rates due to, for example, competition for territory and food (Keeley, 2001; Richard et al., 2015). These density-dependent effects are usually detected via impaired growth (Richard et al., 2015). For riverine populations of cyprinid fish populations in temperate rivers, density-dependent processes tend to be less evident, due in part to the influence of climatic factors during the early-life phases of cohorts that regulates their recruitment, often resulting in low survivorship and, subsequently, relatively low competition for food resources (Nunn et al., 2003, 2007). In these fish communities, environmental factors (e.g. river flow, temperature) and changes in water chemistry (e.g. nutrient enrichment arising from anthropogenic disturbances) tend to be more important influences on fish ecology generally and growth specifically (Lappalainen et al., 2008; Britton et al., 2013).

Spatially, the influence of latitude on water temperature is recognised as a major determinant of fish growth rates in the northern hemisphere (Blanck and Lamouroux, 2007; Lappalainen et al., 2008; Carmona-Catot et al., 2011), with a general pattern of reduced growth with increased latitude due to lower temperatures and shorter growth seasons ((Blanck and Lamouroux 2007; Lappalainen et al., 2008; Carmona-Catot et al., 2011). Nevertheless, anthropogenic activities that modify physical habitats and water quality can also strongly influence growth rates due to the shifts in geomorphic, hydrologic and chemical characteristics of rivers that result in significant changes in the structure and function of fish communities (Welcomme et al., 2006; Beardsley and Britton, 2012; Britton et al., 2013). Moreover, considerable interspecific differences are often evident (Magalhães et al., 2003; Šimková et al., 2006) with, for example, species such as roach Rutilus rutilus tending to grow faster and dominate lowland river fish communities receiving high nutrient loads (Willemsen, 1980; Beardsley and Britton, 2012), with species such as European barbel Barbus barbus increasing their growth rates and importance in communities as loadings decrease (Britton et al., 2013). Nevertheless, there remains considerable spatial uncertainty over the respective responses of species within cyprinid fish communities to these anthropogenic disturbances (Britton, 2007).

Fish growth rates vary throughout their life due to the resource trade-off between growth and other life history traits (Roff, 2000). The trade-off between growth and reproductive traits is particularly important (Roff, 1983, 2000; Britton et al., 2013), with juvenile fish investing energy primarily in somatic growth to maximise their early-life growth and ontogenetic development; with sexual maturity, increased energy is invested in gonad development, reducing somatic growth rates and, potentially, shifting the intensity of how exogenous factors influence 
their growth patterns (Partridge et al., 1991; Glazier, 1999). Consequently, the response of fish growth rates to abiotic variables might show considerable variability across different life phases, such as between juveniles and adults (Roff, 1983, 2000).

The aim of this study was to thus identify how growth rate metrics for a range of cyprinid fishes were impacted by environmental parameters and water chemistry. Focusing on R. rutilus, dace Leuciscus leuciscus and chub Squalius cephalus, the study areas were a series of lowland rivers in England that were also used in the study of Britton et al., (2013) on B. barbus, thus enabling comparison of growth rate patterns across four cyprinid species. The objectives were to: (i) identify spatial patterns in the growth rates of these species over their life-span and in their juvenile life stages; and (ii) test the influence of a range of environmental and chemical parameters on these spatial growth patterns. We test the hypothesis that latitude and water chemistry have significant influences on the growth rates of these fishes, with faster growth rates at lower latitudes and in rivers with metrics indicating improved water quality.

\section{MATERIALS AND METHODS}

\section{> FISH POPULATION SAMPLING AND INITIAL DATA ANALYSES}

The study was based on the rivers used in Britton et al. (2013) which used data on B. barbus growth rates from 13 rivers in England for which sufficient abiotic data were also available for subsequent testing (Tables I and II). Their actual locations in England are available in Britton et al. (2013). The data used here for $R$. rutilus,S. cephalus and used $L$. leuciscus were available from stock assessment exercises completed by the Environment Agency of England in 2005, with each river sampled once using DC electric fishing (hand-held or boat mounted depending on the size of the river). All fish captured were netted and processed before being returned to the river, where processing involved fish identification to species, measuring fork length (nearest $\mathrm{mm}$ ) and removing 3 to 5 non-regenerated scales for subsequent age and growth analysis. In these surveys, sexual differentiation of the fishes could not be completed and so the growth analyses are for combined sexes.

Scales were aged on a projecting microscope; to minimise errors in age estimation, a quality control procedure was utilised as described in Musk et al. (2006) and all scales were viewed for an individual fish prior to its age determination. Agreement in ages during the quality control procedure were always above $90 \%$ for fish up to the age of 6 years old but were reduced thereafter; values for each age then varied between 65 and $89 \%$ with a general pattern of reduced agreement with age. The age ranges of the species also varied, with $R$. rutilus present in samples to age 14 years, S. cephalus to 18 years and L. leuciscus to 8 years, with their annual growth increments decreasing markedly with age, with minimal increases at advanced ages. This combination of this decreased growth and issues with age agreement meant that data for older fish in samples were not included in subsequent analyses, with $R$. rutilus and $S$. cephalus included up to 10 years and $L$. leuciscus 6 years. Following ageing of the scales, they were measured to allow lengths at age to be derived by back-calculation using the scale proportional method (Francis, 1990).

For each species in each river, the growth analyses were completed by determining two measures of growth rate, with statistical complications (e.g. auto-correlation, pseudo-replication) from using repeated measurements from individual fish in the same test (i.e. all growth increments gained from back-calculated lengths) eliminated by use of only one growth metric per individual fish in subsequent analyses (Beardsley and Britton, 2012). The first growth metric was the determination of the mean standardized growth residuals for each river per species (Jones, 2000; Benstead et al., 2007; Storm and Angillett, 2007). For each species, this required the length at age data for all rivers (restricted upper ages; rationale already described), with the mean length at each age determined using the log-log quadratic function of Vilizzi and Walker (1999) who identified this as the most precise and biologically meaningful growth model of five quadratic functions (Vilizzi et al., 2013). Whilst the von Bertalanffy growth model could have been used as an alternative for this, a preliminary examination of its use revealed 


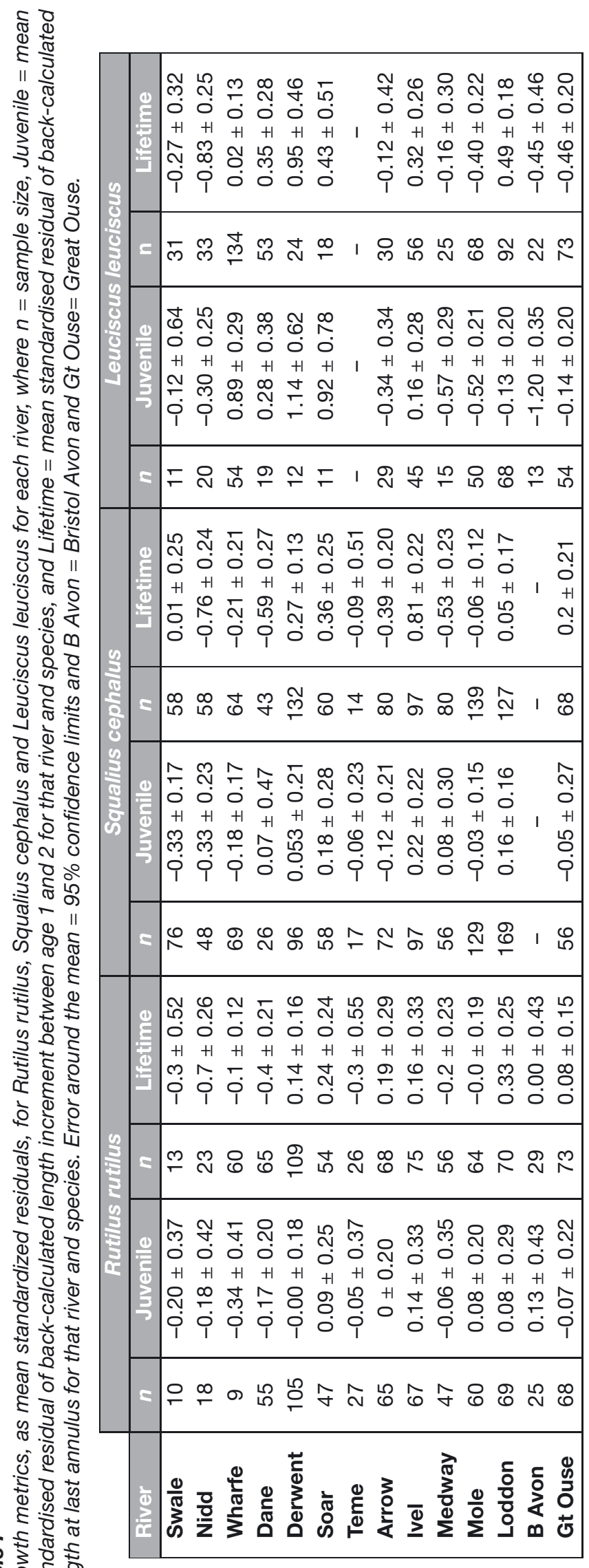


Table II

Abiotic data, expressed as mean standardized residuals for each river, that were used for testing against the fish growth metrics (cf. Table I) and where B Avon = Bristol Avon and Gt Ouse= Great Ouse .

\begin{tabular}{|l|c|c|c|c|}
\hline River & Latitude & BMWP & Nitrate & Ammonia \\
\hline Swale & 1.63 & 0.36 & -1.15 & -0.82 \\
Nidd & 1.63 & 1.42 & -1.61 & -0.5 \\
Wharfe & 1.18 & -0.91 & -1.51 & -0.51 \\
Dane & 0.73 & 0.68 & 0.25 & 0.69 \\
Derwent & 0.29 & 1.07 & -0.6 & 1.46 \\
Soar & 0.29 & -0.76 & 1.29 & 2.56 \\
Teme & -0.16 & 0.33 & -0.68 & -0.89 \\
Arrow & -1.05 & -0.24 & 0.34 & 0.03 \\
Ivel & -0.16 & -1.87 & 0.9 & 0.04 \\
Medway & -1.05 & 0.01 & 1.67 & -0.8 \\
Mole & -1.05 & -0.53 & 0.53 & 0.35 \\
Loddon & -1.05 & -1.42 & 0.52 & -0.76 \\
B Avon & -1.05 & 1.2 & 0.07 & -0.1 \\
Gt Ouse & -0.16 & 0.65 & -0.02 & -0.74 \\
\hline
\end{tabular}

minimal differences in the estimates of mean length from age using both models and so the use of the log-log quadratic function was personal preference of the authors. These values then enabled the standardized residual of the length at age of each fish to calculated (Britton et al., 2010; Beardsley and Britton, 2012), enabling calculation of mean standardized residuals per river that were used to subsequently test the effects of the abiotic factors on the growth rate of each species.

The second growth metric was focused on the growth increment produced between age 1 and 2 years, the rationale being that: (i) using length at age 1 as the increment might be affected by the timing of adult spawning and multiple spawning events in S. cephalus (Bolland et al., 2007), resulting in variability in the duration of the growth season for 0+ fish that was unlikely to be related to abiotic variables alone; and (ii) between age 1 and 2 , the focal species are, generally, still sexually immature at this latitude (e.g. Lappalainen et al., 2008) and so energy resources for growth are used primarily for somatic growth, rather than gonad growth (in contrast to fish of age $>2$ years). This growth metric (hereafter referred to as "juvenile" growth) was calculated by calculating the annual growth increment from the back-calculated lengths at age 1 and 2 of each fish. For each species, the mean increment and standard deviation was calculated, enabling the increment for each individual fish to then be represented as a standardized residual. The mean standardized residual for each river was then calculated and used to subsequently test against the abiotic data.

\section{> INFLUENCE OF ABIOTIC FACTORS ON FISH GROWTH}

The availability of abiotic data for testing against the growth data for each species used actual data from each river and for water temperature, a surrogate dataset, as temperature data were not available. These surrogate temperature data were the latitude and longitude of each site, with air temperature not used as it was co-correlated with both variables, whereby temperatures decreased significantly from south to north, and from east to west (Britton et al., 2013). For water chemistry, the data available were mean concentrations of ammonia, nitrate and phosphate (as orthophosphate) over the study period, and biological water quality as expressed as mean values of the biological monitoring working party score (BMWP) where higher values indicate higher biological water quality (Hawkes, 1998). These data were available as means from data collected by the Environment Agency between 2004 and 2006 from the study reaches (Environment Agency, 2013). Co-linearity was evident in the data between BMWP and phosphate and so only BMWP was used in subsequent analyses. 
For each factor, their mean value and standard deviation was determined for all rivers, with values for individual rivers then expressed as their standardised residual for the purposes of testing against the standardised growth residuals.

Univariate regression was initially used to identify the relationships between the growth and abiotic data. To then identify the abiotic variables that explained most of the variation in the growth metrics of each species, stepwise multiple linear regression was used where the dependent variable was the mean standardized residuals for each river and the independent variables inputted into the model were latitude, longitude, ammonia, nitrate and BMWP. The final model provided the significant predictor variables and their standardized beta coefficients $(\beta)$, where the variable with the highest $\beta$ value having the strongest singular contribution to the final model.

\section{RESULTS}

Across the dataset, 785 R. rutilus, 1087 S. cephalus and 658 L. leuciscus were used in the growth analyses (Table I). As their ages increased, the lengths of each species significantly increased $\left(R\right.$. rutilus: $R^{2}=0.88 ; F_{2,782}=2787.59, P<0.01$; . cephalus: $R^{2}=0.91 ; F_{2,1084}=$ 5483.95, $P<0.01$; L. leuciscus: $R^{2}=0.90 ; F_{2,655}=2951.85, P<0.01$; Figure 1 ). Annual growth increments were still evident at the maximum age included in analyses (Figure 1). There was considerable variability in the back-calculated length at the last annulus of each species (Table I). When analysed as mean standardised residuals, these varied between -0.70 (River Nidd) and 0.33 (River Loddon) in R. rutilus, -0.76 (River Nidd) to 0.81 (River Ivel) in S. cephalus, and -0.83 (River Nidd) to 0.95 in L. leuciscus (River Derwent) (Table I). High variability in the length increment produced between age 1 and 2 years was also evident in each species, with the mean increments ranging between 12 and $77 \mathrm{~mm}$ in $R$. rutilus, 19 and $99 \mathrm{~mm}$ in S. cephalus and 19 and $93 \mathrm{~mm}$ in L. leuciscus. When analysed as mean standardised residuals, their values ranged between -0.34 (River Wharfe) and 0.14 (River Ivel) for $R$. rutilus, -0.33 (River Swale) and 0.22 (River Ivel) for S. cephalus, and -1.20 (Bristol Avon) and 1.14 (River Derwent) for L. leuciscus (Table I). Relationships of patterns of growth rates between the species revealed that the juvenile growth $(\mathrm{J})$ and back-calculated length $(\mathrm{BC})$ at the last annulus of $R$. rutilus and $S$. cephalus were significantly related $\left(\mathrm{J}: R^{2}=0.52\right.$; $\left.F_{1,10}=12.09, P<0.01 ; \mathrm{BC}: R^{2}=0.47 ; F_{1,10}=9.84, P<0.01\right)$. However, the growth rates of $B$. barbus and $L$. leuciscus were not significantly related to those of any other species $(P>0.05$ in all cases).

The growth rate metrics for $R$. rutilus were both significantly related to latitude $\left(\mathrm{J}: R^{2}=0.55\right.$; $F_{1,11}=14.49, P<0.01$; BC: $R^{2}=0.35 ; F_{1,11}=6.35, P<0.05$; Figure 2), with growth rates reducing with increasing latitude. BMWP also had a significant influence on their backcalculated length at the last annulus $\left(R^{2}=0.31 ; F_{1,11}=5.33, P<0.05\right.$; Figure 3$)$, with nitrate being significantly related to their juvenile growth $\left(R^{2}=0.46 ; F_{1,11}=10.14, P<0.01\right.$; Figure 4). The stepwise multiple linear regression models were significant for both growth metrics of $R$. rutilus (J: adjusted $R^{2}=0.64 ; F_{1,11}=12.40, P<0.01$; BC: adjusted $R^{2}=0.29$; $\left.F_{1,11}=6.35, P<0.05\right)$, with latitude explaining most of the variability in the growth data (J: $\beta=-0.76, P<0.01$; BC: $\beta=-0.59, P<0.05)$.

The juvenile growth of $S$. cephalus was negatively associated with latitude $\left(R^{2}=0.35 ; F_{1,10}=\right.$ 5.82, $P<0.05$; Figure 2) and nitrate $\left(R^{2}=0.65 ; F_{1,10}=20.16, P<0.01\right.$; Figure 4$)$, with these relationships not apparent for their back-calculated length at the last annulus $(P>0.05$; Figures 2 and 4). The relationships of BMWP and ammonia levels with their growth metrics were not significant $(P>0.05$ in all cases; Figures 3 and 5). The multiple linear regression model for juvenile $S$. cephalus growth was significant (adjusted $R^{2}=0.62 ; F_{1,10}=20.16$, $P<0.01)$, with nitrate explaining most of the variability in the growth data $(\beta=0.80, P<0.01)$. The multiple regression model for their back-calculated length at the last annulus was not significant $(P>0.05)$, with no significant explanatory variables $(P>0.05)$.

The relationships of $L$. leuciscus growth rates with latitude, BMWP and nitrate were all not significant $(P>0.05$ in all cases; Figures 2-4). Ammonia levels were, however, significantly 

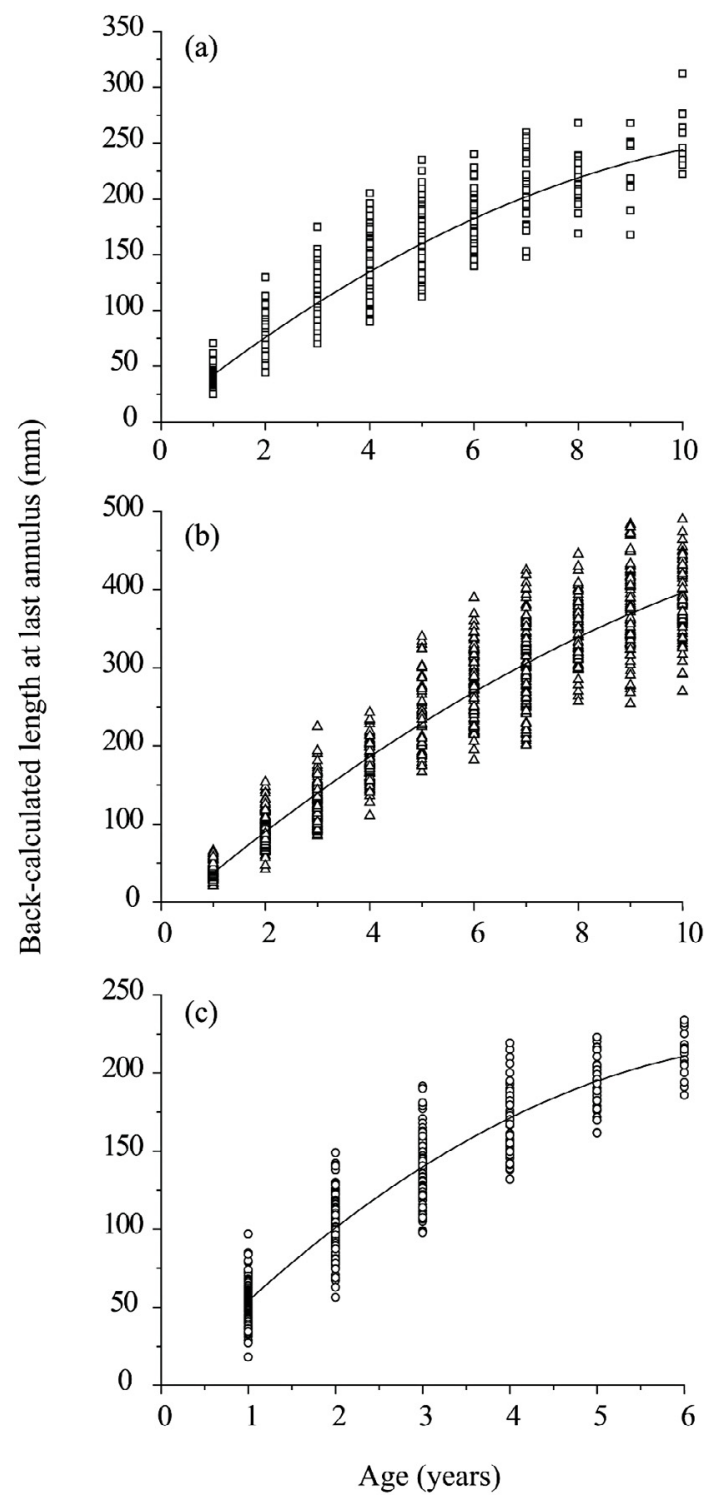

Figure 1

Back-calculated lengths at the last annulus of (a) Rutilus rutilus, (b) Squalius cephalus, and (c) Leuciscus leuciscus, The solid line represents the growth curves fitted by the quadratic function for each fish species.

related to both growth metrics $\left(\mathrm{J}: R^{2}=0.32 ; F_{1,10}=5.28, P<0.05 ; \mathrm{BC}: R^{2}=0.32 ; F_{1,10}=\right.$ 5.15, $P<0.05$; Figure 5). Stepwise multiple linear regression models for their juvenile growth and back-calculated length at the last annulus were both significant (J: adjusted $R^{2}=0.26$; $F_{1,10}=5.28, P<0.05 ;$ BC: adjusted $\left.R^{2}=0.26 ; F_{1,10}=5.15, P<0.05\right)$, with ammonia concentration being the most important predictor $(\mathrm{J}: \beta=0.57, P<0.05$; $\mathrm{BC}$ : $\beta=0.57$, $P<0.05)$.

\section{DISCUSSION}

Variability in the growth rate metrics of $R$. rutilus, S. cephalus and L. leuciscus was apparent across the dataset. This variability was also apparent in the growth rates of $B$. barbus in the same rivers (Britton et al., 2013). Whilst this demonstrates that a key feature of these cyprinid fishes was high plasticity in their growth rates, and by extension, aspects of their life history 

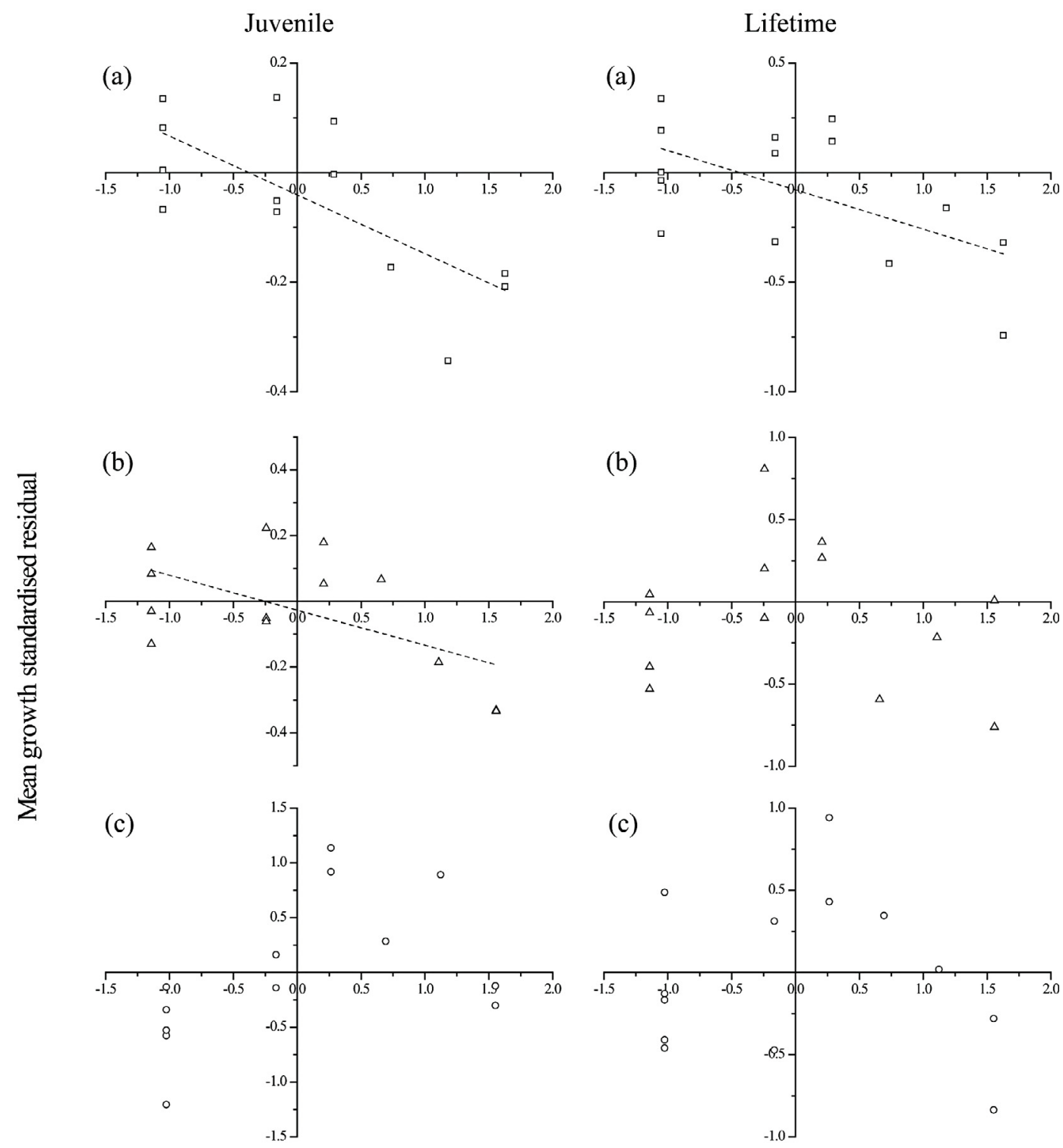

Latitude standardised residual

\section{Figure 2}

The relationships of mean standardised growth residuals of (a) Rutilus rutilus, (b) Squalius cephalus, and (c) Leuciscus leuciscus with those for latitude in all rivers. Significant relationships (cf. Results; $P<0.05)$ are indicated by the dashed line. Juvenile: mean standardised residual of back-calculated length increment between age 1 and 2; Lifetime: mean standardised residual of back-calculated length at last annulus.

strategies, it did not necessarily follow that where there was a fast growing population of one species in a river, the other species were similarly fast growing (or the converse), with the growth rates of $L$. leuciscus and $B$. barbus not correlating with those of the other species. This suggests the growth plasticity relates, at least in part, to species-specific responses to the abiotic conditions encountered across the 13 rivers and corresponds with the hypothesis that latitude ( as a surrogate of temperature) and water chemistry had significant influences on the growth rates of these fishes. Nevertheless, potential errors in the dataset could have been incurred by the ageing of scales lacking a validation method, thus impacting these outputs (Beamish and McFarlane, 1983). However, errors in ageing precision were minimised by the quality control procedure (Musk et al., 2006), although where future work is completed to 

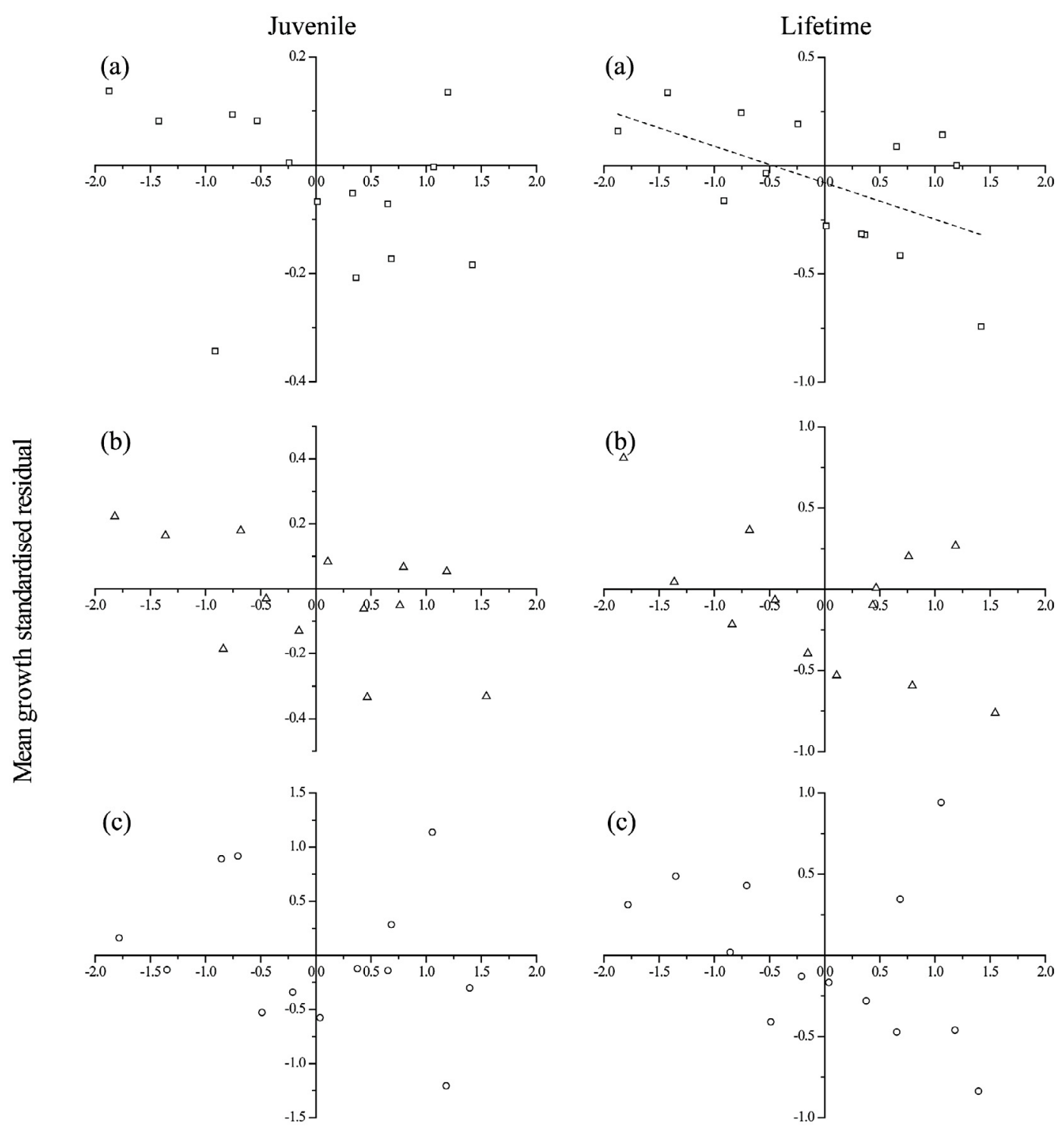

BMWP standardised residual

\section{Figure 3}

The relationships of mean standardised growth residuals of (a) Rutilus rutilus, (b) Squalius cephalus, and (c) Leuciscus leuciscus with those for BMWP in all rivers. Significant relationships (cf. Results; $P<$ $0.05)$ are indicated by the dashed line. Juvenile: mean standardised residual of back-calculated length increment between age 1 and 2. Lifetime: mean standardised residual of back-calculated length at last annulus.

build on the outputs of this study at larger spatial scales then it could include some validation either through mark-recapture or the use of some alternative structures to assist the scale ageing, such as otoliths (Campana, 2001).

For $R$. rutilus, outputs of multiple regression suggested that even over the relatively small latitudinal range of England (i.e. 50 to $54^{\circ} \mathrm{N}$ ), latitude was the significant predictor of their growth rate variability, as per the hypothesis, with decreased growth rates with increasing latitude. This output is consistent with the meta-analysis on roach life history traits of Lappalainen et al. (2008), who revealed that the asymptotic lengths and growth coefficients of their populations were inversely correlated with latitude between $50{ }^{\circ} \mathrm{N}$ and $64^{\circ} \mathrm{N}$. Thus, this pattern observed over a relatively large latitudinal gradient was also detected over a much smaller 

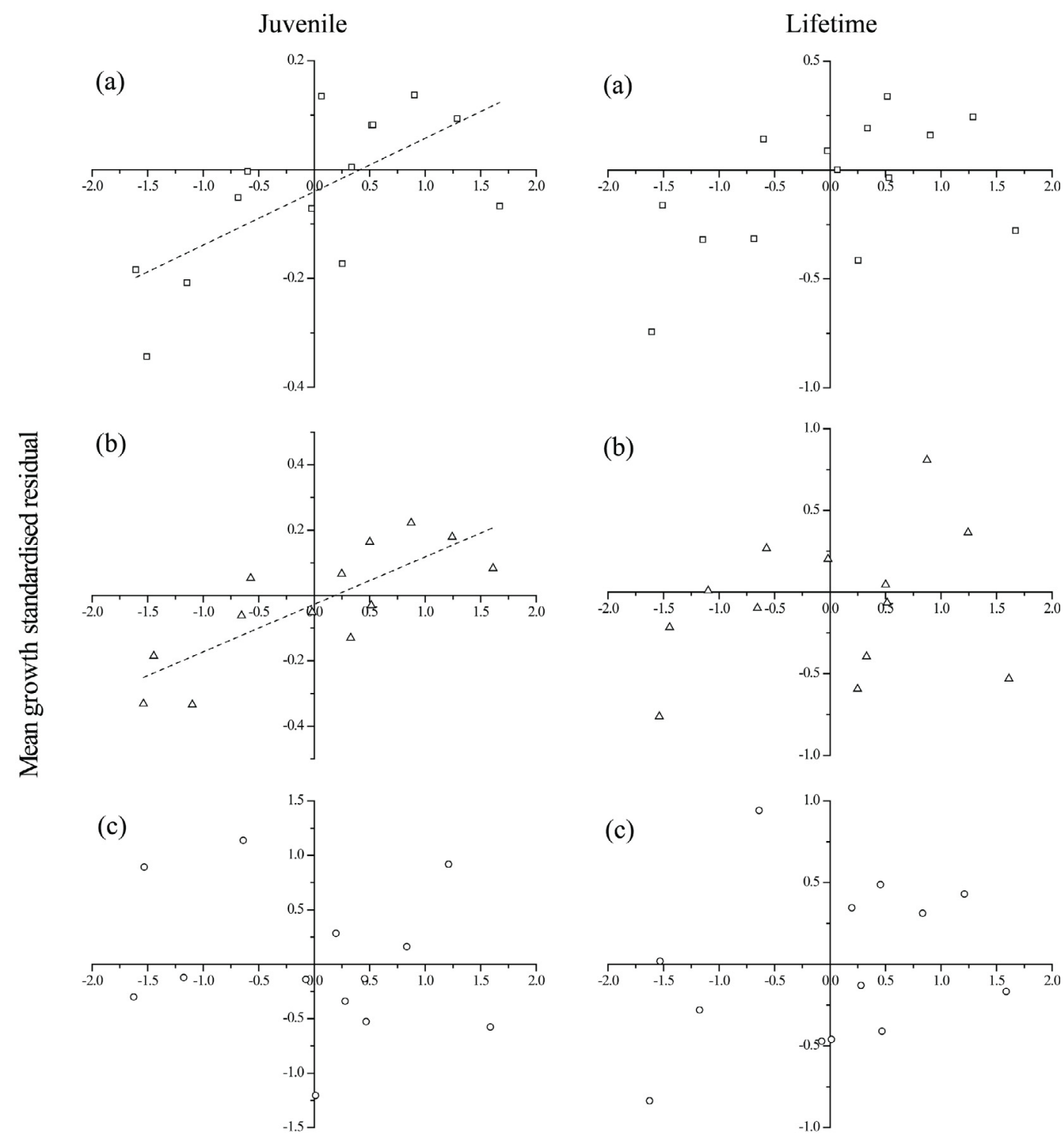

Nitrate standardised residual

\section{Figure 4}

The relationships of mean standardised growth residuals of (a) Rutilus rutilus, (b) Squalius cephalus, and (c) Leuciscus leuciscus with those for nitrate in all rivers. Significant relationships (cf. Results; $P<$ $0.05)$ are indicated by the dashed line. Juvenile: mean standardised residual of back-calculated length increment between age 1 and 2. Lifetime: mean standardised residual of back-calculated length at last annulus.

gradient, emphasising the importance of latitudinal (and so temperature) gradients on their growth patterns. The juvenile growth of $S$. cephalus also significantly reduced with increasing latitude, with this consistent with Tedesco et al. (2009) who suggested higher temperatures were coincident with faster chub growth rates in a study comparing 15 populations along a longitudinal river gradient. There was, however, no relationship between their back-calculated length at the last annulus and latitude, suggesting that latitude (and thus temperature) was a more important influence on their juvenile growth. For L. leuciscus, latitude was not a significant predictor of their growth rate metrics and thus either the interplay of latitude and air temperature has little influence on their growth or it was unable to be detected over the relatively small latitudinal gradient of this study. 
Juvenile
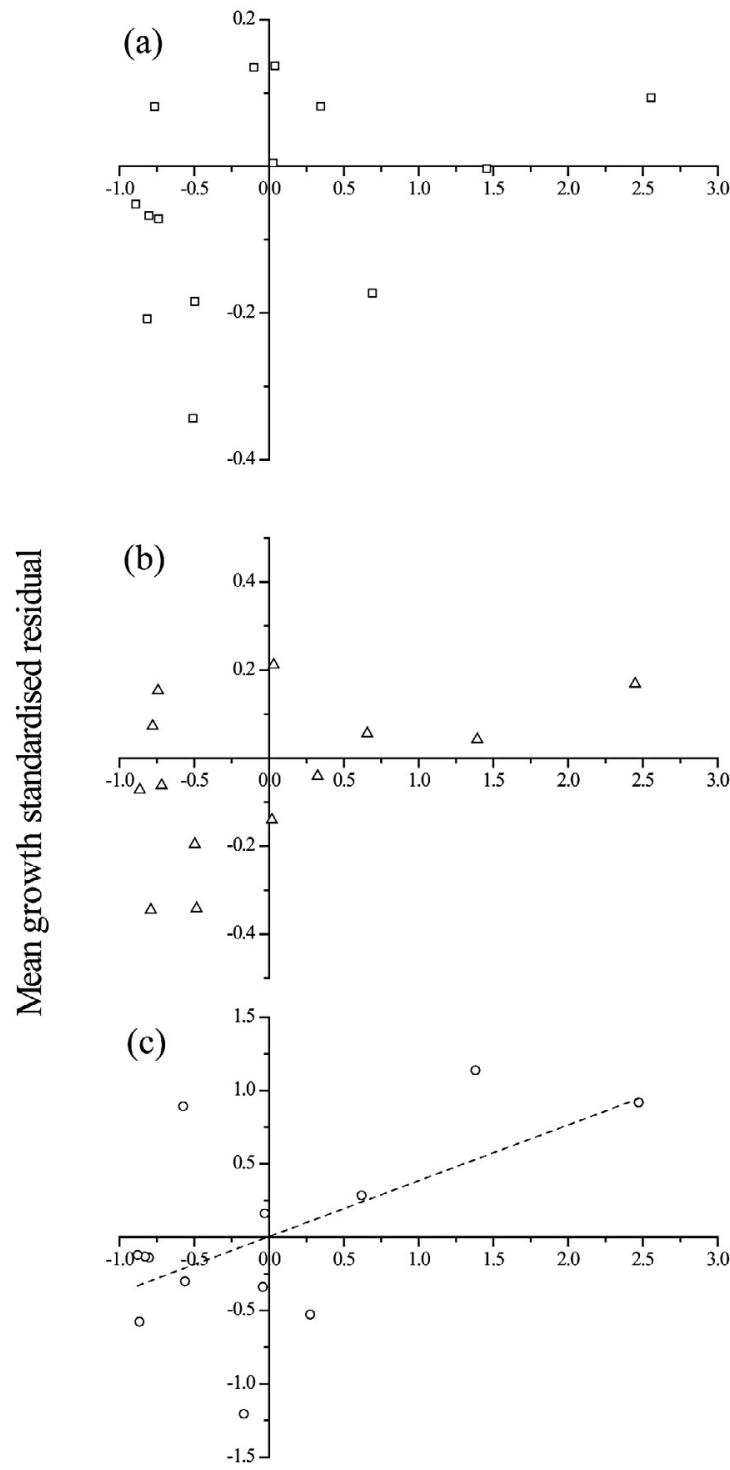

Lifetime
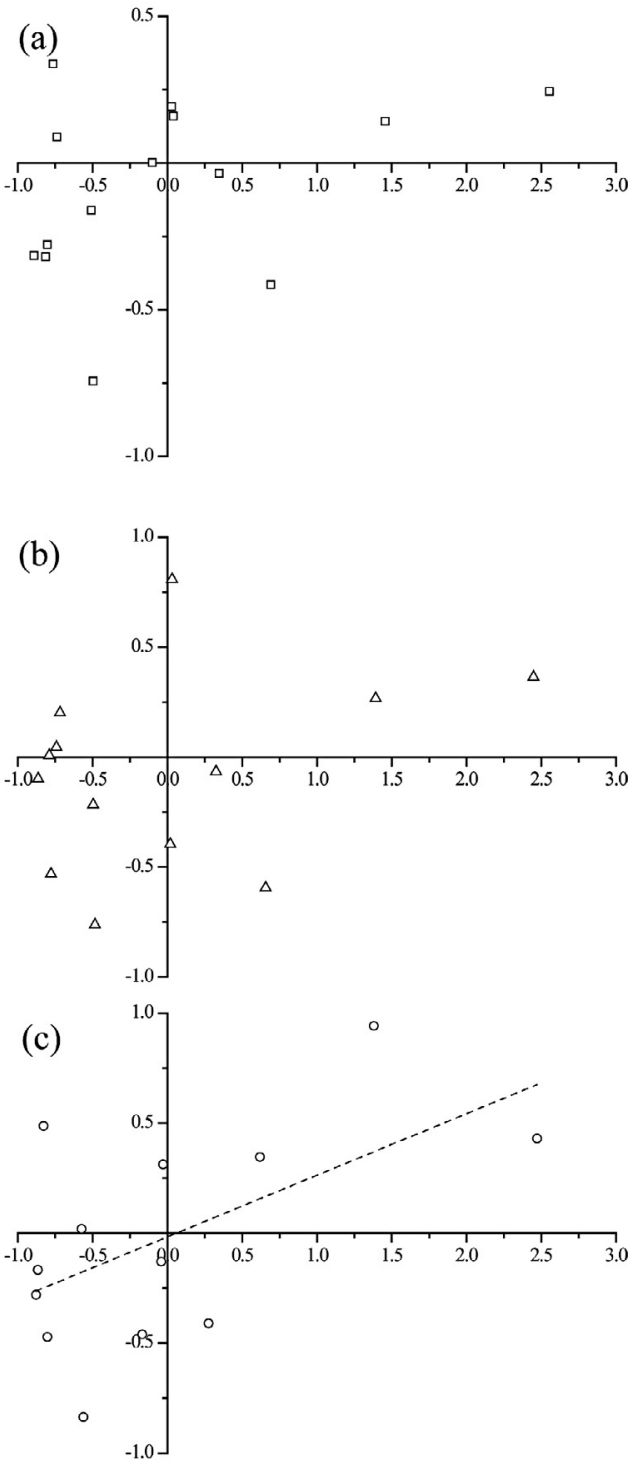

Ammonia standardised residual

\section{Figure 5}

The relationships of mean standardised growth residuals of (a) Rutilus rutilus, (b) Squalius cephalus, and (c) Leuciscus leuciscus with those for ammonia in all rivers. Significant relationships (cf. Results; $P<0.05)$ are indicated by the dashed line. Juvenile: mean standardised residual of back-calculated length increment between age 1 and 2. Lifetime: mean standardised residual of back-calculated length at last annulus.

Aspects of the water quality of the rivers had some significant influences on the growth rates of the three fishes in this study. However, contrary to the hypothesis, higher growth rates were not apparent in rivers with higher water quality but the converse, with faster growth rates of some species as, for example, biological water quality reduced (as lower BMWP scores). Although this was not the case for B. barbus in these rivers (Britton et al., 2013), so emphasising the species-specific specific responses to these parameters, it has been generally established that cyprinid fishes tend to dominate freshwaters with relatively high nutrient loadings (Lappalainen et al., 2001), with faster growth of species, including $R$. rutilus, often being apparent when the organic loadings of rivers are relatively high (Beardsley and Britton 2012). 
Whilst nitrogenous compounds can have adverse impacts on fish growth rates, particularly in aquaculture systems (e.g. Beamish and Tandler, 1990; Crab et al., 2007), that this was not apparent over the 13 rivers here might relate to two issues. Firstly, Wood (2004) revealed that, when under toxicity thresholds, fish growth rates are often positively related to ammonia concentrations as they stimulate protein synthesis without increasing food consumption, thus leading to higher growth rates. Secondly, Xin et al. (2010) suggested that nitrate and ammonia have significant and positive effects on microalgae growth, thus directly influencing productivity and indirectly increasing the overall food resources available to the fishes. Nevertheless, the effects of these nitrogenous compounds were not consistent across the four species, with $L$. leuciscus being the only species whose growth rates were positively and significantly correlated with mean ammonia concentrations.

There were differences in how the abiotic data influenced the two growth metrics of the fishes. Across the dataset, five significant relationships were detected between juvenile growth rates and the abiotic variables, with this reducing to three for the back-calculated length at the last annulus, suggesting the influence of abiotic factors on juvenile growth were more marked. The causal consequences might relate to the energy trade-off between growth and reproduction, whereby in their early life history, fish tend to allocate more resources to somatic growth and thus this represents the life stage when somatic growth rates are most susceptible to being affected by environmental parameters (Partridge et al., 1991; Glazier, 1999). This is important, as this early life growth will then influence other life history traits such as age and length at maturity, and influence their life span (Vila-Gispert and Moreno-Amich, 2002; Blanck and Lamouroux, 2007). Following maturity, there is increased investment in reproductive traits (Lester et al., 2004), somatic growth rates decrease and thus the potential influence of environmental and chemical variables on growth rates appears to decrease.

In summary, across these 13 rivers, the three cyprinid fishes analysed here, plus $B$. barbus (Britton et al., 2013), exhibited considerable intra-specific differences in their somatic growth rates, with this variability at least partially related to the response of the populations to the environmental and chemical parameters of each river. Given that fish growth rates have been used widely to assess the influences of anthropogenic activities on aquatic environments (e.g. Harris, 1995; Welcomme et al., 2006), then these data assist assessment of how environmental changes might alter the growth rates of cyprinid fishes against a backdrop of influences of vairables such as temperature (latitude). Indeed, providing that toxicity thresholds are not exceeded then our outputs suggest that the expression of some aspects of the life history traits of these species, such as somatic growth rates, will shift and, potentially, accelerate.

\section{ACKNOWLEDGEMENTS}

CL was sponsored by the Erasmus Mundus programme "TECHNO".

\section{REFERENCES}

Beamish R.J. and McFarlane, G.A., 1983. The forgotten requirment for age validation in fisheries biology. Trans. Am. Fish. Soc., 112, 735-743.

Beamish F. and Tandler A., 1990. Ambient ammonia, diet and growth in lake trout. Aquat. Toxicol., 17, 155-166.

Beardsley H. and Britton J.R. 2012 Contribution of temperature and nutrient loading to growth rate variation of three cyprinid fishes in a lowland river. Aquat. Ecol., 46, 143-152.

Benstead J.P., Green A.C., Deegan L.A., Peterson B.J., Slavik K., Bowden W.B. and Hershey A.E., 2007. Recovery of three arctic stream reaches from experimental nutrient enrichment. Freshwater Biol., 52, 1077-1089.

Berkeley S.A., Hixon M.A., Larson R.J. and Love M.S., 2004. Fisheries sustainability via protection of age structure and spatial distribution of fish populations. Fisheries, 29, 23-32. 
Blanck A. and Lamouroux N., 2007. Large-scale intraspecific variation in life-history traits of European freshwater fish. J. Biogeogr., 34, 862-875.

Bolland J., Britton J.R. and Cowx I.G., 2007 Lifetime consequences of variable 0 year group length in riverine populations of chub Leuciscus cephalus (L.). J. Fish Biol., 71,1810-1819.

Brandt S.B., Mason D.M. and Patrick E.V., 1992. Spatially-explicit models of fish growth rate. Fisheries, 17, 23-35.

Britton J., 2007. Reference data for evaluating the growth of common riverine fishes in the UK. J. Appl. Ichthyol., 23, 555-560.

Britton J.R., Davies G.D. and Harrod C., 2010. Trophic interactions and consequent impacts of the invasive fish Pseudorasbora parva in a native aquatic foodweb: a field investigation in the UK. Biol. Invasions, 12, 1533-1542.

Britton J.R., Davies G.D. and Pegg J., 2013. Spatial variation in the somatic growth rates of European barbel Barbus barbus: a UK perspective. Ecol. Freshw. Fish, 22, 21-29.

Campana, S.E., 2001. Accuracy, precision and quality control in age determination, including a review of the use and abuse of age validation methods. J. Fish Biol., 59, 197-242.

Carmona-Catot G., Benito J. and García-Berthou E., 2011. Comparing latitudinal and upstreamdownstream gradients: life history traits of invasive mosquitofish. Divers. Distrib., 17, 214-224.

Crab R., Avnimelech Y., Defoirdt T., Bossier P. and Verstraete W., 2007. Nitrogen removal techniques in aquaculture for a sustainable production. Aquaculture, 270, 1-14

Environment Agency, 2013. What's in your Backyard? http://apps.environment-agency.gov.uk/wiyby/ default.aspx Last accessed 23/03/2015.

Francis R., 1990. Back-calculation of fish length: a critical review. J. Fish Biol., 36, 883-902.

Glazier D., 1999. Trade-offs between reproductive and somatic (storage) investments in animals: a comparative test of the Van Noordwijk and De Jong model. Evol. Ecol., 13,539-555.

Harris J.H., 1995. The use of fish in ecological assessments. Aust. J. Ecol., 20, 65-80.

Hawkes H.A., 1998. Origin and development of the biological monitoring working party score system. Water Res., 32, 964-968.

Jones C.M., 2000. Fitting growth curves to retrospective size-at-age data. Fish Res., 46, 123-129.

Keeley E.R., 2001. Demographic responses to food and space competition by juvenile steelhead trout. Ecology, 82,1247-1259.

Lappalainen A., Rask M., Koponen H. and Vesala S., 2001. Relative abundance, diet and growth of perch(Perca fluviatilis) and roach(Rutilus rutilus) at Tvaerminne, northern Baltic Sea, in 1975 and 1997: responses to eutrophication? Boreal Environ. Res., 6, 107-118.

Lappalainen J., Tarkan A.S. and Harrod C., 2008. A meta-nalysis of latitudinal variations in life-history traits of roach, Rutilus rutilus, over its geographical range: linear or non-linear relationships? Freshwater Biol., 53, 1491-1501.

Lester N., Shuter B., Abrams P., 2004. Interpreting the von Bertalanffy model of somatic growth in fishes: the cost of reproduction. Proc. R. Soc. Lond. Biol., 271, 1625-1631.

Magalhães M., Schlosser I. and Collares-Pereira M., 2003. The role of life history in the relationship between population dynamics and environmental variability in two Mediterranean stream fishes. J. Fish Biol., 63, 300-317.

Musk R., Britton J.R. and Axford S., 2006. The effect of subjective fish scale ageing on growth and recruitment analyses: a case study from the UK. Acta Ichtyol. Pisc., 36, 81-84.

Nunn A., Cowx I., Frear P. and Harvey J.P., 2003. Is water temperature an adequate predictor of recruitment success in cyprinid fish populations in lowland rivers? Freshwater Biol., 48, 579-588.

Nunn A., Harvey J., Britton J.R., Frear P. and Cowx I.G., 2007. Fish, climate and the Gulf Stream: the influence of abiotic factors on the recruitment success of cyprinid fishes in lowland rivers. Freshwater Biol., 52, 1576-1586.

Partridge L., Sibly R., Beverton R. and Hill W., 1991. Constraints in the evolution of life histories. Proc. R. Soc. Lond. Biol., 332, 3-13.

Richard A., Cattanéo F. and Rubin J.F., 2015. Biotic and abiotic regulation of a low-density streamdwelling brown trout (Salmo trutta L.) population: effects on juvenile survival and growth. Ecol. Freshw. Fish, 24, 1-14. 
Roff D.A., 1983. An allocation model of growth and reproduction in fish. Can. J. Fish. Aquat. Sci., 40, 1395-1404.

Roff D.A., 2000. Trade-offs between growth and reproduction: an analysis of the quantitative genetic evidence. J. Evol. Biol., 13, 434-445.

Šimková A., Ottová E. and Morand S., 2006. MHC variability, life-traits and parasite diversity of European cyprinid fish. Evol. Ecol., 20, 465-477.

Storm M.A. and Angilletta M.J., 2007. Rapid assimilation of yolk enhances growth and development of lizard embryos from a cold environment. J. Exp. Biol. 210, 3415-3421.

Tedesco P.A., Sagnes P. and Laroche J., 2009. Variability in the growth rate of chub Leuciscus cephalus along a longitudinal river gradient. J. Fish Biol., 74, 312-319.

Vila-Gispert A. and Moreno-Amich R., 2002. Life-history patterns of 25 species from European freshwater fish communities. Environ. Biol. Fish., 65, 387-400.

Vilizzi L. and Walker K.F., 1999. Age and growth of the common carp, Cyprinus carpio, in the River Murray, Australia: validation, consistency of age interpretation, and growth models. Environ. Biol. Fish., 54, 77-106.

Vilizzi L., Copp G.H. and Britton J.R., 2013. Age and growth of European barbel Barbus barbus (Cyprinidae) in the small, mesotrophic River Lee and relative to other populations in England. Knowl. Manag. Aquat. Ecosyst., 09.

Welcomme R., Winemiller K. and Cowx I.G., 2006. Fish environmental guilds as a tool for assessment of ecological condition of rivers. River Res. Appl., 22, 377-396.

Willemsen J., 1980. Fishery-aspects of eutrophication. Aquat. Ecol., 14, 12-21.

Wood C.M., 2004. Dogmas and controversies in the handling of nitrogenous wastes: Is exogenous ammonia a growth stimulant in fish? J. Exp. Biol., 207, 2043-2054.

Xin L., Hong Y.H., Ke G. and Jia Y., 2010. Growth and nutrient removal properties of a freshwater microalga Scenedesmus sp. LX1 under different kinds of nitrogen sources. Ecol. Eng., 36, 379-381.

Cite this article as: C. Liu, Y. Chen and J.R. Britton, 2015. Influences of environmental and chemical parameters on the spatial growth patterns of four riverine cyprinid fishes. Knowl. Manag. Aquat. Ecosyst. , 416, 12. 